\title{
Development of a Surplus Value Parameter for Use in Initial Aircraft Conceptual Design
}

\author{
Peter Hollingsworth ${ }^{\mathrm{i}}$ and Dipesh Patel ${ }^{\mathrm{ii}}$ \\ The University of Manchester, Manchester, M13 9PL
}

\begin{abstract}
Simple constraints analysis, as taught to most aerospace engineering students gives little guidance as to exactly which design point should be selected. There is a recent body of work that attempts to solve this for initial designs, without having to fully size the new aircraft concept. The best of these focuses on maximizing a 'Range Parameter' which leads to minimizing gross weight for transport aircraft. However, this is not guaranteed to maximize the value of the new design. This paper presents a corresponding surplus value parameter which is design to provide just that capability. Furthermore, it shows that in at least some cases the resulting optimum design point will shift from that suggested by the range parameter.
\end{abstract}

\section{Nomenclature}

$C_{i} \quad=$ Cost

$C P_{i} \quad=$ Cost parameter

$D_{i} \quad=$ Discount multiplier

$H_{i} \quad=$ Hours

$M_{\max } \quad=$ Maximum Mach number

$N_{\text {Eng }} \quad=$ Number of engines

$N_{\text {market }}=$ Annual Market Size

$Q \quad=$ Total number of aircraft

$R \quad=$ Range/Rate/Revenue

$R P \quad=$ Range parameter

$S V \quad=$ Surplus value

$S V P \quad=$ Surplus value parameter

$T_{\text {Block }}=$ Block time

$T_{\max }=$ Maximum thrust, per engine

$t_{i} \quad=$ Programme duration or product life

$\left.\frac{T}{W}\right|_{S L, 0} \quad=$ Thrust to weight ratio, sea-level, static

$U=$ Annual utilization

$V \quad=$ Maximum velocity/Velocity

$W_{i} \quad=$ Weight

$\left.\frac{W}{S}\right|_{0} \quad=$ Wing-loading, max gross weight

$0=\quad=$ Max gross, beginning of mission

$\mathrm{AF} \quad=$ airframe

$c \quad=$ customer

crew $=$ crew

$D=$ development support

dev = development

$E \quad=$ Engineering

$e \quad=$ empty

Eng = engine

\footnotetext{
' Lecturer in Aerospace Engineering, School of MACE, George Begg Building, Sackville Street.

ii Student, School of MACE, George Begg Building, Sackville Street.
} 


$\begin{array}{ll}F & =\text { Fuel/Flight test support } \\ f & =\text { fuel, per gallon } \\ \text { flight } & =\text { per flight } \\ \text { Fuel } & =\text { Fuel, per flight } \\ \text { man } & =\text { manufacturing } \\ \text { matl } & =\text { materials } \\ m t c & =\text { maintenance } \\ p & =\text { producer } \\ P L & =\text { payload } \\ Q C & =\text { quality control } \\ T & =\text { tooling } \\ \alpha & =\text { Thrust lapse } \\ \beta & =\text { Mission weight fraction } \\ \alpha_{0 / 1} & =\text { Empty weight multiplier } \\ \beta_{0} & =\text { Empty weight exponent } \\ \sigma_{i} & =\text { discount rate }\end{array}$

\section{Introduction}

The use of a thrust-to-weight vs. wing-loading constraints diagram is a standard way for aircraft conceptual design explorations to be launched. Historically, this has been attempted to assist in getting a good initial condition via which an aircraft can be sized and synthesised. One of the issues with the standard constraint analysis is that any measure of goodness is inherently crude, minimise $\mathrm{T} / \mathrm{W}$ and maximise $\mathrm{W} / \mathrm{S}$. Further, it is nearly impossible to select and initial design point for some aircraft types as no trade between T/W and W/S can be determined from the information contained. One solution to this is to periodically revisit the constraint diagram after actually sizing the aircraft, producing contours or thumbprints on the constraint diagram or a similar Thrust vs. MTOW chart ${ }^{1,2}$. McDonald ${ }^{3}$ identified a significant problem with this in that one has to actually size the aircraft to produce these charts. As such this requires some level of parametric sizing capability such as that provided by programs such as NASA's FLOPS ${ }^{4,5}$. In order to alleviate this issue some authors have proposed using $L / D^{6}$ and $M(L / D)^{3,6}$ as a surrogate for the sized aircraft. However, these only consider the aerodynamic performance of the aircraft. McDonald ${ }^{3}$ further proposes the use of either a Range Parameter (RP) and/or Endurance Parameter (EP).

The RP approach, which also includes that ability to estimate the optimum cruise speed and altitude. This approach is typically based upon selecting a simple and straightforward weight fraction for the cruise, McDonald used $0.8^{3}$. However, while this may make sense for simple sizing to minimize MTOW at a maximum range and payload it does not represent the reality of how aircraft are typically operated, in shorter range and payload conditions ${ }^{7}$. This means that for many operations the applicable cruise weight fraction may actually be a fair bit lower.

Further, while the RP and EP measures may lead to aircraft that have the lowest possible MTOW for the design, they do not guarantee the best possible value to either the operator or manufacturer. To ensure this it is necessary to use a more 'sophisticated', value-driven approach ${ }^{8-11}$. The value approach looks at both the traditional performance of the aircraft and the actual operating environment, including maintenance, manufacturing and design and development considerations into account.

\section{Background}

The development of a surplus value parameter for use in very early conceptual design is based upon the prior work of developing a range parameter, plus the principles behind conceptual cost modelling and surplus value. In order to progress further it is necessary to identify and understand each of these.

\section{A. Range Parameter}

McDonald ${ }^{3}$ defined the Range Parameter (RP) in terms of the different characteristics of the conceptual aircraft. Normally, performance codes use the Specfic Range (SR), shown in Eq. 1, to illustrate the instantaneous efficiency of the entire flight vehicle as a specific flight condition. While 
the SR is quite useful, the appropriate flight conditions are not always something that is known apriori in the conceptual phase.

$$
S R \equiv \frac{V}{C_{T} D}
$$

What is more often known, at least for the unconstrained cruise operations, in conceptual design is the thrust specific fuel consumption $\left(c_{T}\right)$ and the cruise lift-to-drag ratio $(L / D)$. Expanding from the range equation, see Eq. 2, it is possible to pull out the performance parameters in the form of the RP, Eq. 3.

$$
\begin{aligned}
& R=\frac{V}{c_{T}} \frac{L}{D} \ln \left(1+\frac{W_{f}}{W_{p}+W_{e}}\right) \\
& R P \equiv \frac{V}{c_{T}} \frac{L}{D}
\end{aligned}
$$

The units of the range parameter are in terms of pure distance, i.e. that is how far the aircraft can be flown for the natural log of the inverse of the weight fraction.

In addition to the range parameter McDonald ${ }^{3}$ also proposed an equivalent formulation for endurance, the Endurance Parameter (EP). This is shown in Eq. 4.

$$
E P \equiv \frac{1}{c_{T}} \frac{L}{D}
$$

McDonald fully investigates the different uses and permutations of the range and endurance parameters, most of which while useful, are beyond the scope of this paper. This paper will restrict the use of range parameter to the case where Mach and altitude can be optimally chosen at all times.

\section{B. Surplus Value}

Surplus value (SV) has been well defined by several previous authors. This paper uses the same basic form first described by Collopy ${ }^{12}$ and formalised by Hollingsworth ${ }^{11}$. This form is given in Eq. 5 .

$S V=D_{P} N_{\text {market }}\left[D_{C} U\left(R_{\text {flight }}-C_{\text {flight }}\right)-C_{\text {Man }}\right]-C_{\text {Dev }}$

Hollingsworth ${ }^{11}$ goes into detail regarding the calculations of discount multipliers, $D_{P} \& D_{C}$. However, the simplest form of the discount multipliers is given in Eq. 6 .

$$
D_{i}=\frac{1}{\sigma_{i}}-\frac{1}{\sigma_{i}\left(1+\sigma_{i}\right)^{t_{i}}}
$$

The beauty of the SV formulation is that it allows for a relatively simple ranking of different engineering options on a financial basis without having to perform detailed future forecasts. If models for estimating costs based on extensive engineering attributes exist then it is relatively straightforward to link these attributes to the SV function. The only one of the SV inputs that cannot be easily given to engineers or determined by engineering analysis is the revenue per flight. However, most design choices being considered, especially rubber designs are not going to significantly affect the revenue generated. Consequently, since we are more interested in the rank order it is possible to leave out the revenue entirely. This gives Eq. 3.

$$
S V_{\text {cost }}=D_{P} N_{\text {market }}\left[D_{C} U\left(C_{\text {flight }}\right)-C_{\text {Man }}\right]-C_{\text {Dev }}
$$

It must be noted that for the cases where revenue changes for different conceptual designs, e.g. those described by Sutcliffe and Hollingsworth ${ }^{10}$, then this simplification cannot be made.

\section{Cost Modelling}

In order to capture the potential surplus value of a product it is necessary to model the costs. While there are a number of cost models available, for the purposes of this paper the authors propose that a simple, weight regressed cost approach be used. The reasons for this are multiple. One, it is not always possible to full understand the actual activities involved in the construction of a new design at the conceptual/constraint analysis phase. Two, different organisations have different approaches and regression factors for their cost models. Regardless, it is relatively straightforward to demonstrate the approach with a published approach and alter it as necessary to fit a new model. The model used for this research is the DAPCA IV model developed by RAND ${ }^{13-15}$ and modified by Raymer $^{1}$. It consists of estimators for the manufacturing cost and development and testing. These are given in Eqs. 8-19.

$$
\begin{aligned}
& H_{E}=4.86 W_{e}^{0.777} V^{0.894} Q^{0.163} \\
& H_{T}=5.99 W_{e}^{0.777} V^{0.696} Q^{0.263} \\
& H_{M}=7.37 W_{e}^{0.82} Q^{0.641}
\end{aligned}
$$




$$
\begin{aligned}
& H_{Q C}=0.133 H_{M} \\
& C_{D}=89.10 W_{e}^{0.630} V^{1.3} \\
& C_{F}=2438.452 W_{e}^{0.325} V^{0.822} F T A^{1.21} \\
& C_{\text {matl }}=21.58 W_{e}^{0.921} V^{0.621} Q^{0.799} \\
& C_{E N G}=3644.05\left[0.043 T_{\text {Max }}+243.25 M_{\text {Max }}-2228\right] \\
& C_{\text {Avionics }}=0.20 \times \text { Final aircraft cost } \\
& C_{\text {Dev }}=C_{D}+C_{F} \\
& C_{\text {Man,Total }}=H_{E} R_{E}+H_{T} R_{T}+H_{M} R_{M}+H_{Q C} R_{Q C}+C_{\text {matl }}+C_{E N G} N+C_{\text {AVIONICS }} \\
& C_{\text {Man }}=\frac{C_{\text {Man,Total }}}{Q}
\end{aligned}
$$

The quantity $(Q)$, empty weight $\left(W_{e}\right)$, maximum velocity $(V)$ and Mach number $\left(M_{\text {Max }}\right)$, and engine maximum thrust $\left(T_{\text {Max }}\right)$ are the basic contributors to these costs. Quantity is also directly related to the market size, i.e. it is the sum of all the aircraft produced and sold over the course of the programme plus any prototypes that are not sold. Meanwhile, thrust and empty weight are directly related to both the constraints diagram and the sizing of the aircraft.

Operating costs are typically split into direct and indirect operating costs. These can be computed on either a per-hour or per-flight basis. Depending on which method is used, the specific value of utilization in the SV equation is either flights per annum or hours per annum. The indirect costs are generally insensitive to the design of the aircraft. As a consequence they only serve to shift the SV up or down as a constant and are not necessary to rank order different designs. As such, the indirect costs are excluded from the method presented in this paper. Regardless of the specific form of estimation, there are four basic direct costs: fuel, crew, maintenance and fees. Using models developed by Liebeck et al. ${ }^{16}$, the basic fuel, crew and maintenance costs are given in Eqs 20-31.

$T_{\text {Block }}=(0.0021 \times$ Distance +0.94$)$

$C_{\text {Fuel }}=\frac{W_{f}}{\rho_{f}} C_{f}$

where: $\rho_{f}=6.7 \frac{l b}{\text { gallon }}$

$C_{\text {Crew }, \text { Flight }}=3.08\left(440+0.590\left(\frac{W_{0}}{1000}\right)\right) T_{\text {Block }}$

$C_{\text {Crew, } \text { Cabin }}=38.62\left[2+\left(\frac{\left(N_{\text {Seats }}\right)-100}{50}\right)\right] T_{\text {Block }}$

$C_{\text {crew }}=C_{\text {Crew,Flight }}+C_{\text {Crew,Cabin }}$

$C_{M t c, A F, L a b o u r}=$

$38.62\left\{\left[1.26+1.774\left(\frac{W_{\text {Airframe }}}{10^{5}}\right)-0.1071\left(\frac{W_{\text {Airframe }}}{10^{5}}\right)^{2}\right] T_{\text {Block }} U+\left[1.614+0.7227\left(\frac{W_{\text {Airframe }}}{10^{5}}\right)+\right.\right.$

0.1204 WAirframe 1052

$C_{M t c, A F, M a t l}=$

$1.54\left[\left(12.39+29.8\left(\frac{W_{\text {Airframe }}}{10^{5}}\right)+0.1806\left(\frac{W_{\text {Airframe }}}{10^{5}}\right)^{2}\right) T_{\text {Block }} U+\left(15.2+97.33\left(\frac{W_{\text {Airframe }}}{10^{5}}\right)-\right.\right.$

2.862WAirframe1052

$C_{M t c, A F}=\left(C_{M t c, A F, \text { Labour }}+C_{M t c, A F, \text { Matl }}\right) /_{U}$

$C_{\text {Mtc,Eng,Labour }}=38.62\left(0.645+\left(\frac{0.05 \times T_{\text {Max }}}{N_{\text {Eng }} \times 10^{4}}\right)\left(0.566+\frac{0.434}{T_{\text {Block }} U t_{C}}\right)\right) T_{\text {Block }} U N_{\text {eng }}$

$C_{\text {Mtc,Eng,Matl }}=1.54\left(25+\left(\frac{0.05 \times T_{\text {Max }}}{N_{\text {Eng }} \times 10^{4}}\right)\left(0.62+\frac{0.38}{T_{\text {Block }} U t_{C}}\right)\right) T_{\text {Block }} U N_{\text {eng }}$

$C_{M t c, \text { Eng }}=\left(C_{M t c, \text { Eng }, \text { Labour }}+C_{M t c, \text { Eng,Labour }}\right) /_{U}$

$C_{m t c}=C_{M t c, A F}+C_{M t c, E n g}$ 
The fees themselves are strictly a function of maximum gross weight $\left(W_{0}\right)$ and are given in Eqs. 32 to 34.

$$
\begin{aligned}
& C_{\text {Ldg }}=6.25 \times\left(W_{0} / 1000\right) \\
& C_{\text {nav }}=0.20 \times 500 \times \sqrt{\frac{W_{0}}{1000}} \\
& C_{f e e}=C_{L d g}+C_{\text {nav }}
\end{aligned}
$$

with the resulting cost per flight shown in Eq. 35.

$C_{\text {flight }}=C_{\text {Fuel }}+C_{\text {crew }}+C_{m t c}+C_{\text {fee }}$

\section{SV Model in Constraint Analysis}

Like the RP approach it is necessary to capture the essence of an aircraft design, in a surplus value approach, without having to size and design for the entire mission. Unfortunately, given the results in Eq. it is not strictly possible to produce a single value for SV without sizing an aircraft. What can be done is to look at the factors that affect the surplus value and eliminate those that are less significant for the typical aircraft programme. Revisiting Eqs. $6 \& 7$ we see that the primary effectors of SV are the number sold, the utilization, programmatic factors such as discount rates and expected durations and the individual cost components. The individual cost components, in the simplified models, are all functions of a combination of $W_{0}, W_{e}, W_{f}$, or $T$ plus a series of other parameters that are a function of operating speeds, payload and market size. Keeping in mind that the max take-off weight is a function of these variables, shown in Eq 36 , it is possible to define $W_{0}$ and consequently $\frac{W_{0}}{S}$ as a function of these.

$$
W_{0}=W_{f}+W_{e}+W_{p l}
$$

Combining Eqs. 2, $3 \& 26$ we get the take-off weight as a function of the range parameter, shown in Eq. 37.

$$
W_{0}=\left(W_{p l}+W_{e}\right) e^{\frac{R}{R P}}
$$

This can be combined with Eq. $38^{17}$, which gives a simple relationship between empty weight and gross weight to form Eq. 39.

$$
\begin{aligned}
& W_{e}=\alpha_{0} W_{0}^{1+\beta_{0}} \\
& W_{0}=\frac{W_{p} e^{\frac{R}{R P}}}{1-\alpha_{0} W_{0}^{1-\beta_{0}} e^{\frac{R}{R P}}}
\end{aligned}
$$

Obviously, the problem here is that in this formulation $W_{0}=f\left(W_{0}\right)$, this means an iteration must be performed. However, it is possible, to determine ahead of time a rough order for $W_{e}=f\left(W_{0}\right)$. This can be refined as the actual sizing takes place. Replacing Eq. 36 with a form that is purely a fraction of $W_{0}$, Eq. 40, allows Eq 39 to be recast as Eq 41 .

$$
\begin{aligned}
& W_{e} \cong \alpha_{1} W_{e} \\
& W_{0} \cong \frac{W_{p} e^{\frac{R}{R P}}}{1-\alpha_{1} e^{\frac{R}{R P}}}
\end{aligned}
$$

or in terms of $\left.\frac{W}{S}\right|_{0}$ as shown in Eq. 42.

$$
\left.\frac{W}{S}\right|_{0} \cong \frac{W_{p}}{S} \frac{e^{\frac{R}{R P}}}{1-\alpha_{1} e^{\frac{R}{R P}}}
$$

This shows us that as a first order the take-off wing loading is a function of the payload loading and range parameter. Returning to Eqs. 8-14 \& 16-19 it is self evident that the airframe cost is primarily a function of $W_{0}$. Engine cost on the other hand is a function of installed thrust. The development cost can be represented as a function of $\left.\frac{W}{S}\right|_{0}$ as shown in Eq. 43.

$$
\frac{C_{D e v}}{S}=89.10\left(\alpha_{1} \frac{W_{0}}{S}\right)^{0.630} V^{1.3}+2438.452\left(\alpha_{1} \frac{W_{0}}{S}\right)^{0.325} V^{0.822} F T A^{1.21}
$$

A quick review indicates that the first portion of Eq 43 is dominant $\left(C_{D}\right)$, producing values that are typically an order of magnitude or more greater than $\left(C_{F}\right)$, see Figure 1 . This gives a development cost parameter $\left(C P_{D e v}\right)$ that is solely a function of the wing loading. This is shown in Eq. 44.

$$
C P_{\text {Dev }}=100\left(\alpha_{1} \frac{W_{0}}{S}\right)^{0.7}
$$




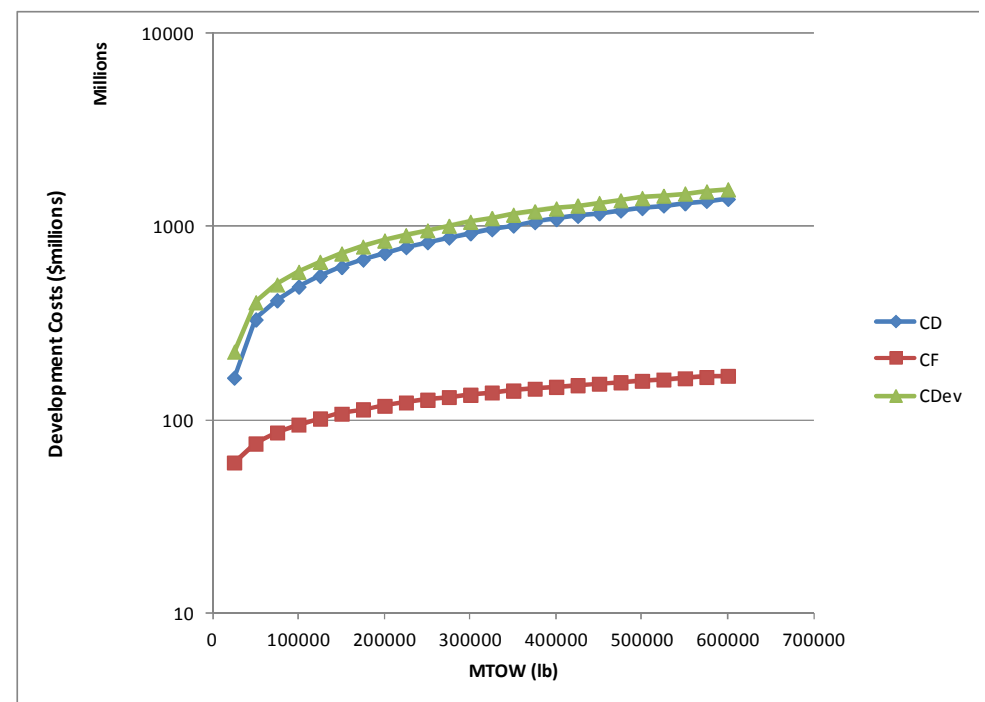

Figure 1: Comparison of Development and Flight Test Costs as a function of MTOW, where $\alpha_{1}=0.48, V=498 \mathrm{kts}$ and $F T A=4$

A similar activity can be undertaken with the manufacturing cost. Equation 19 can be rewritten as $C_{\text {Man }, A F}=4.86 W_{e}^{0.777} V^{0.894} Q^{-0.837} R_{E}+5.99 W_{e}^{0.777} V^{0.696} Q^{-0.737} R_{T}+7.37 W_{e}^{0.82} Q^{-0.359} R_{M}+$ $0.980 W_{e}^{0.82} Q^{-0.359} R_{Q C}+21.58 W_{e}^{0.921} V^{0.621} Q^{-0.201}$

or

$\frac{C_{M a n, A F}}{S}=$

$4.86\left(\alpha_{1} \frac{W_{0}}{S}\right)^{0.777} V^{0.894} Q^{-0.837} R_{E}+5.99\left(\alpha_{1} \frac{W_{0}}{S}\right)^{0.777} V^{0.696} Q^{-0.737} R_{T}+7.37\left(\alpha_{1} \frac{W_{0}}{S}\right)^{0.82} Q^{-0.359} R_{M}+$ $0.980\left(\alpha_{1} \frac{W_{0}}{S}\right)^{0.82} Q^{-0.359} R_{Q C}+21.58\left(\alpha_{1} \frac{W_{0}}{S}\right)^{0.921} V^{0.621} Q^{-0.201}$

Again, one or a few components of the cost tends to dominate, for smaller production size this is the engineering and tooling along with materials cost, see Figure 2.

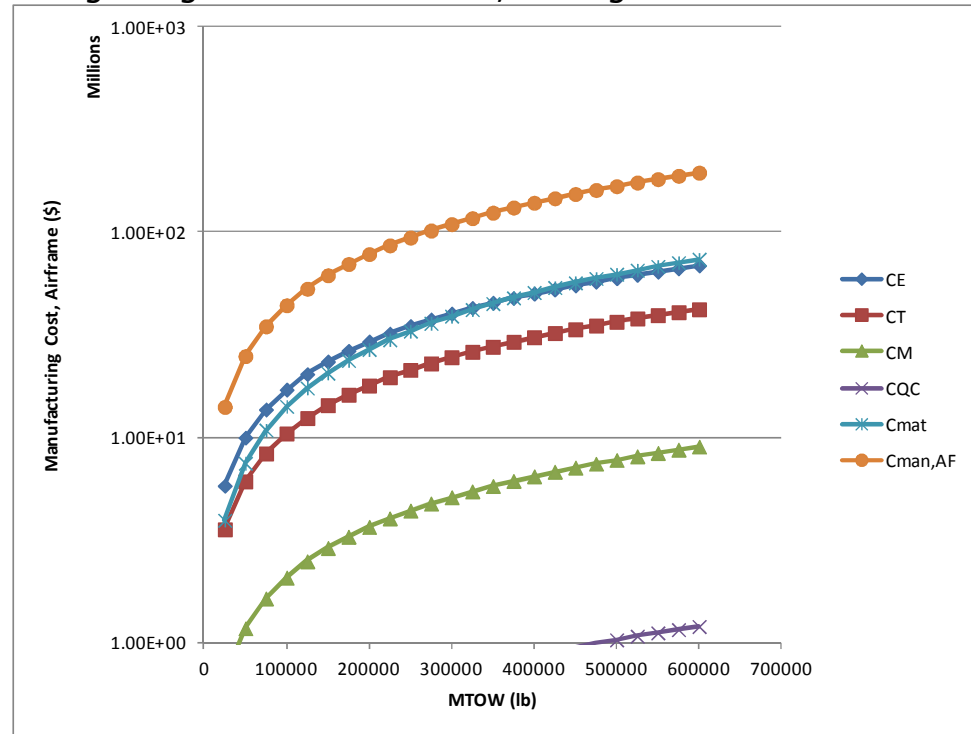

Figure 2: Comparison of Airframe Manufacturing Costs as a function of MTOW, where $\alpha_{1}=0.48, V=498 \mathrm{kts}$ and $Q=1200$

For larger runs, the materials dominate. As such an airframe cost parameter can be approximated in Eq 47.

$C P_{\text {Man }, A F}=20\left(\alpha_{1} \frac{W_{0}}{S}\right)^{1.0} V^{0.9} Q^{-0.36}$

The engine manufacturing cost can also be approximated using a similar cost parameter, Eq. 48.

$C P_{\text {Man, Eng }}=160\left(\frac{T}{W}\right)_{S L, 0}+$ Constant 
While the development and manufacturing costs are directly related to either the wing loading or the thrust to weight ratio the operating costs are proportional to the mission being flown. The fuel consumed, and hence the fuel cost is proportional to e raised to the inverse of the range parameter.

$$
C_{\text {fuel }}=\frac{W_{f}}{\rho_{f}} C_{f} \propto e^{\frac{1}{R P}}
$$

The key is to know how $C_{\text {fuel }}$ relates to other costs. In this case a typical mission weight fraction needs to be calculated. Using Eqs. 2, $36 \& 37$ it is possible to estimate the $W_{f}$ for a mission, shown in Eq. 50.

$$
W_{f}=\left(W_{0}-\frac{W_{0}}{e^{\frac{R}{R P}}}\right)=\left(1-\frac{1}{e^{\frac{R}{R P}}}\right) W_{0}
$$

A cost parameter for fuel would take the form of:

$$
C P_{\text {fuel }}=\frac{C_{f}}{\rho_{f}}\left(1-\frac{1}{e^{\frac{R}{R P}}}\right)\left(\frac{W}{S}\right)_{0}
$$

The crew costs conversely scales with block time, and has no direct relation to the range parameter. This can be represented by a crew cost parameter.

$$
C P_{\text {Crew }}=3.08\left(440+\frac{0.590}{1000}\left(\frac{W}{S}\right)_{0}\right) T_{\text {Block }}
$$

Note, the cabin crew cost is also a relative constant, not directly affected by the $\frac{T}{W}$ or $\frac{W}{S}$ as such, like the revenue it can be excluded.

The final set of costs are the maintenance costs. A review of Eqs. $25 \& 26$ and $28 \& 29$ indicate that they are dominated by the reocurring costs per flight instead of the fixed costs. As such a cost parameter for both the airframe and the engine will be developed that contain only the reoccurring costs. These are given in Eqs. 53 and 54.

$$
\begin{aligned}
& C P_{m t c, A F}=\left\{1.54\left[\frac{29.8}{10^{5}}\left(\left.\alpha_{1} \frac{W}{S}\right|_{0}\right)+\frac{0.1806}{10^{5}}\left(\left.\alpha_{1} \frac{W}{S}\right|_{0}\right)^{2}\right]+36.82\left[\frac{1.77}{10^{5}}\left(\left.\alpha_{1} \frac{W}{S}\right|_{0}\right)-\frac{1.07}{10^{5}}\left(\left.\alpha_{1} \frac{W}{S}\right|_{0}\right)^{2}\right]\right\} T_{\text {block }} \\
& C P_{m t c, \text { Eng }}=\left\{38.62\left(0.645+\frac{0.028}{10^{4}}\left(\frac{T}{W}\right)_{S L, 0}\right)+1.54\left(25+\frac{0.031}{10^{4}}\left(\frac{T}{W}\right)_{S L, 0}\right)\right\} T_{\text {block }}
\end{aligned}
$$

Consequently a surplus value parameter $(S V P)$ can be developed from Eq. 7 and Eqs. 44, 47, 48 and 51-54. This is given in Eq. 55.

$$
\begin{aligned}
& S V P=D_{p} N_{\text {market }}\left[D_{C} U\left(-C P_{\text {fuel }}-C P_{\text {crew }}-C P_{m t c, A F}-C P_{\text {mtc,Eng }}\right)-C P_{\text {man,AF }}-C P_{\text {man,Eng }}\right]- \\
& C P_{\text {Dev }}
\end{aligned}
$$

The result is that ideal thrust to weight and wing loading is dependent on the range parameter and the thrust to weight and wing loadings.

In order to determine the appropriate surplus value parameter response for a given aircraft the following procedure should be used:

1. Determine Constrains as appropriate, this paper uses the Mattingly's ${ }^{17}$ method

2. Calculate Range Parameter using McDonald's method ${ }^{3}$

3. Calculate Surplus Value Parameter using Eqs. 44, 47, 48 and 51-55

\section{Example}

In order to demonstrate the concept of an SV parameter in initial conceptual design it is necessary to use an example of an early conceptual design process. Further, to demonstrate the applicability the results will be compared to both the typical methods taught to engineering students and McDonald's range parameter ${ }^{3}$. For the purposes of this study a simple, current technology 150 passenger class aircraft will be used. The basic engine and aerodynamic decks are obtained from FLOPS internal routines ${ }^{4}$. This allows aerodynamic and propulsion data that is slightly more sophisticated than simple $\frac{L}{D}, T S F C=$ constant, approaches. A further simplification from McDonald ${ }^{3}$ is that this example only investigates the case where the aircraft cruises at optimum altitude and Mach number. While this does not typically replicate the reality of operations it is sufficient for this example. Additionally the aircraft will be subject to four simple constraints. These are given in Table 1. 
Table 1: Basic Aircraft Constraints

\begin{tabular}{|l|l|}
\hline Constraint & Value \\
\hline Service Ceiling & $36,000 \mathrm{ft}$ at $\beta=0.80$ \\
Take-off Ground Roll & $4,000 \mathrm{ft}$ \\
Second Segment Climb, one engine inop & $1.4^{\circ}$ \\
Approach Speed & $130 \mathrm{kts}, \beta=0.75$ \\
\hline
\end{tabular}

Figure 3 contains the aerodynamic and engine performance for the aircraft

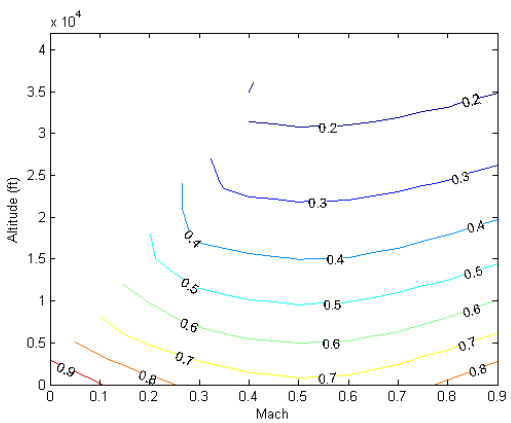

(a) $\alpha_{\max }$ for the engine

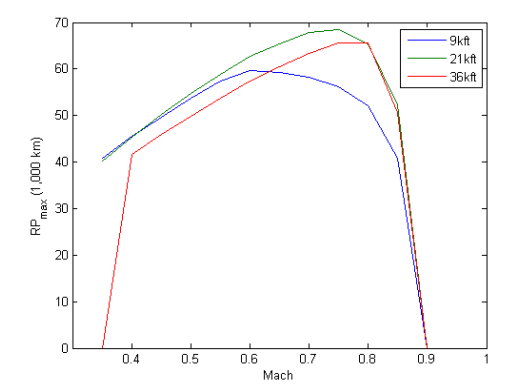

(c) Maximum RP

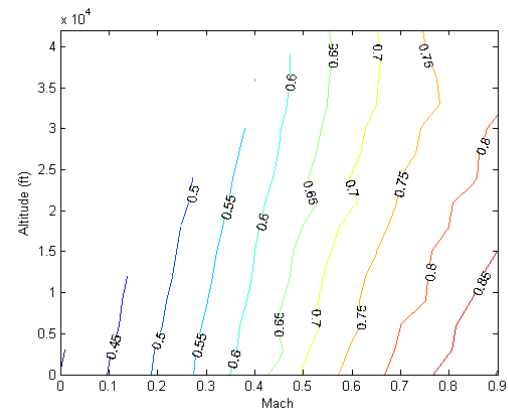

(b) TSFC min at $80 \%$ Throttle

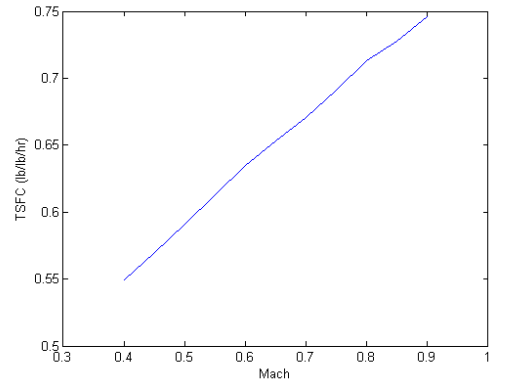

(d) Max thrustTSFC at Tropopause

Figure 3: Aerodynamic and Engine Performance for the Notional 150 Passenger Aircraft

This results in a simple constraints diagram as shown in Figure 4. The problem with this style constraints diagram is that, as most students are taught, it is impossible to select a starting design point. Each point along the Take-off constraint, between the cruise ceiling and approach speed constraints is equally valid. This isn't a problem if the user is completely indifferent to the different points, in which case the designer can choose any one of the points that lies along these lines. 


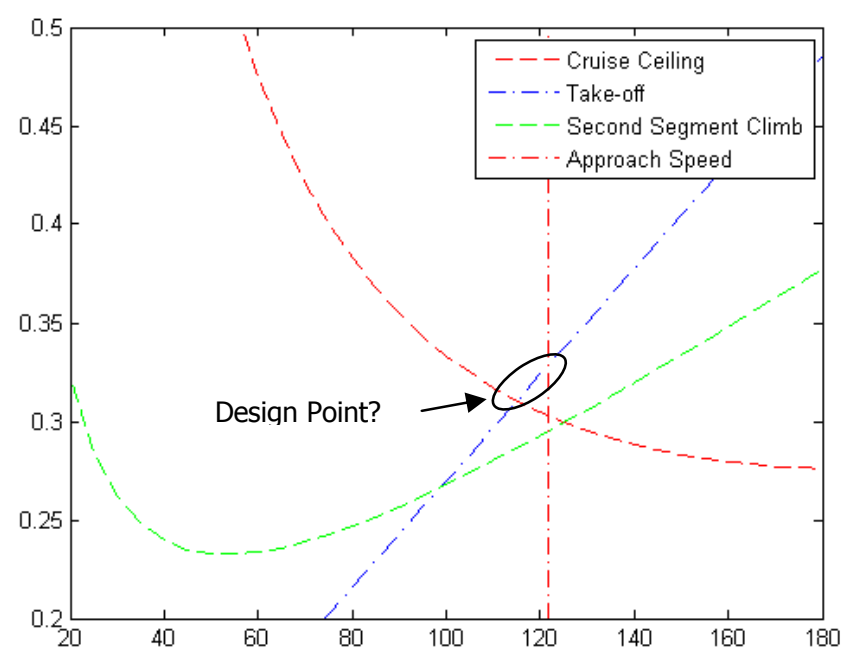

Figure 4: Basic Constraint Analysis for Notional 150 Passenger Aircraft

What happens if the designer wants to minimize the weight of the aircraft? McDonald ${ }^{3}$ has shown that maximizing the Range Parameter approximates the minimum gross weight. For the notional aircraft the maximum range parameter point, shown in Figure 5, is generally at a high wing loading and low thrust to weight ratio.

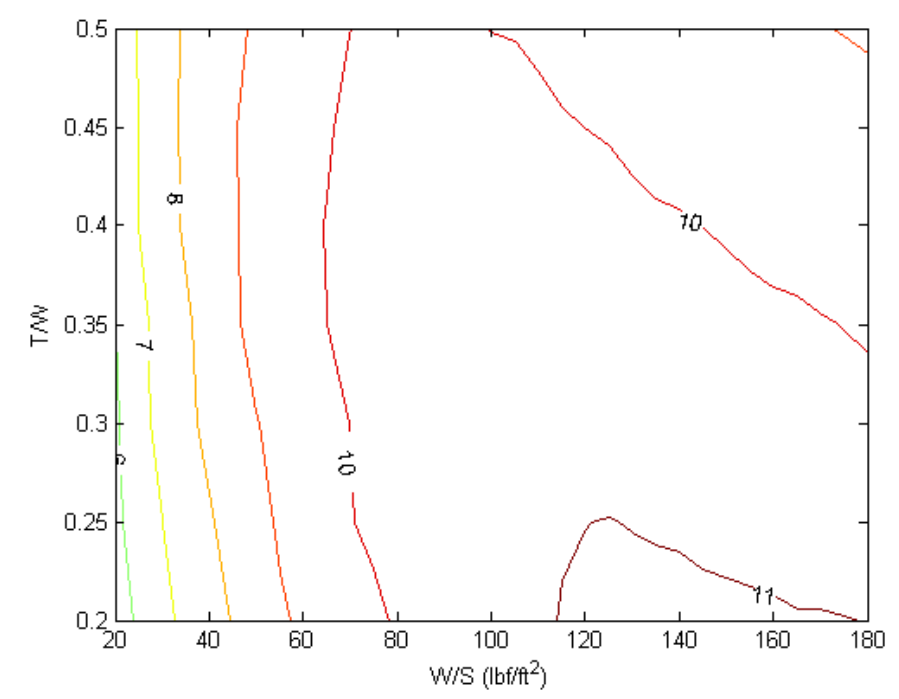

Figure 5: Range Parameter Contours for Notional 150 Passenger Aircraft (1000 nmi)

However, while the general trend holds the specific contours are more complex, forming closed boundaries and not just simple lines. The key is to try and find a point on the constraints boundary that is nearly parallel to one of the range parameter contours. This is shown in Figure 6 . In this case the notional design point, one that minimizes gross weight, shifts to the intersection of the take-off and cruise ceiling constraints as this is essentially parallel to the local range parameter contour. The reader should note that while this specific contour holds true for the notional 150 passenger aircraft, it is not guaranteed for every design and the user should actually use the appropriate values. 


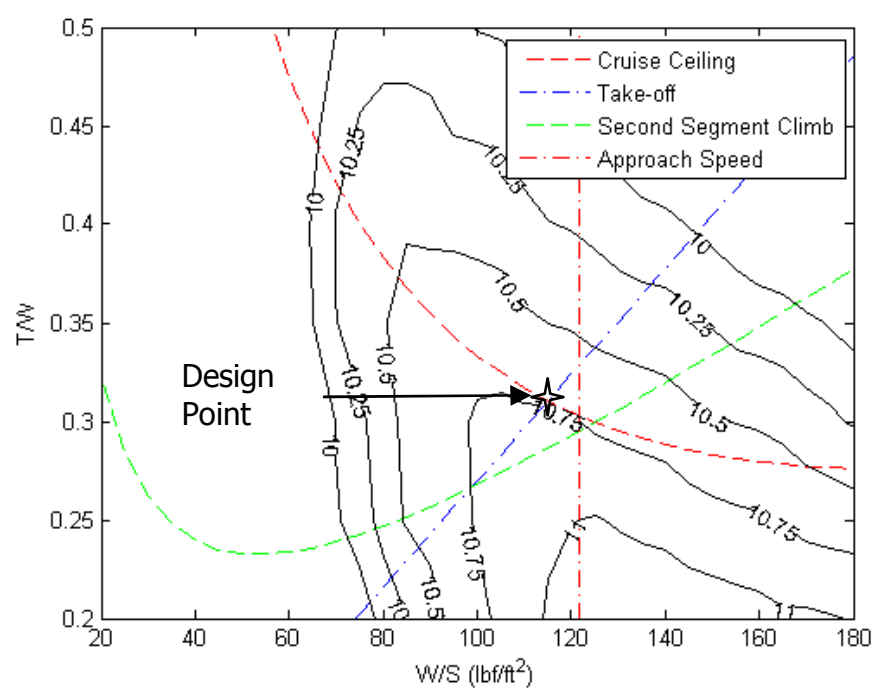

Figure 6: Range Parameter Contours and Constraints for Notional 150 Passenger Aircraft (1000 nmi)

This result is useful for the cases where the goal is purely to minimize gross weight. However, as Collopy and Hollingsworth ${ }^{8}$ have shown this is not necessarily the best design for the firms producing and operating the aircraft.

Moving a step beyond the range parameter to the surplus value parameter it is necessary to define a few more properties of the aircraft and its market. These are given in Table 2, with the resulting surplus value parameter contours shown in Figure 7.

Table 2: Surplus Value Parameter Calculation Market and Business Case Properties

\begin{tabular}{|l|l|}
\hline Property & Value \\
\hline Producer Discount Rate $\left(\sigma_{p}\right)$ & $12.5 \%$ \\
Customer Discount Rate $\left(\sigma_{c}\right)$ & $25 \%$ \\
Programme Duration $\left(t_{p}\right)$ & 15 years \\
Aircraft Life $\left(t_{c p}\right)$ & 20 years \\
Market Size $\left(Q, N_{\text {market }}\right)$ & 3000 aircraft (200/year) \\
Annual Utilization $(U)$ & 1200 flights \\
\hline
\end{tabular}

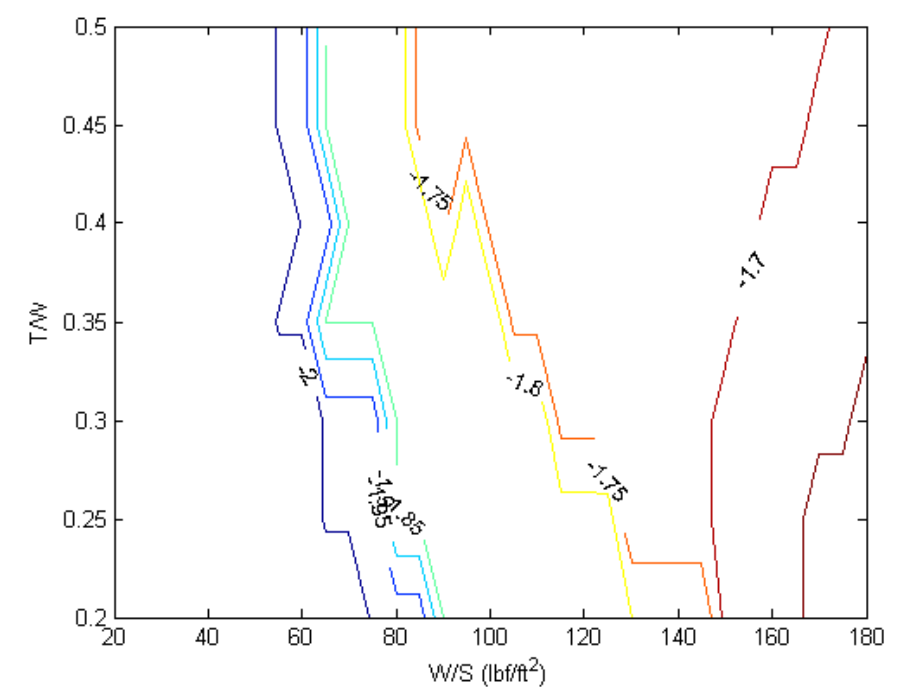

Figure 7: Surplus Value Parameter Contours for Notional 150 Passenger Aircraft $\left(1 \times 10^{10} \$ \mathrm{ft}^{-2}\right)$

The results are highly negative, which is a consequence of the removal of the revenue term in Eq. 7. It is straight forward to adjust these values by a simple constant if the designer feels that this is 
more useful. The reason for this is that we are only trading amongst different designs and not deciding on whether or not we will proceed with a programme. In this case the user wants to maximize the surplus value parameter. While in general the trend is toward higher wing loadings, it is not as sensitive to thrust-to-weight as the range parameter.

Again, in order to select the best starting design point, with respect to a first order assessment of surplus value, it is necessary to superimpose the constraint analysis on the surplus value parameter contours. Once this is done, the user seeks out the point on the constraints that is nearly parallel to the surplus value parameter contours. This is shown in Figure 8.

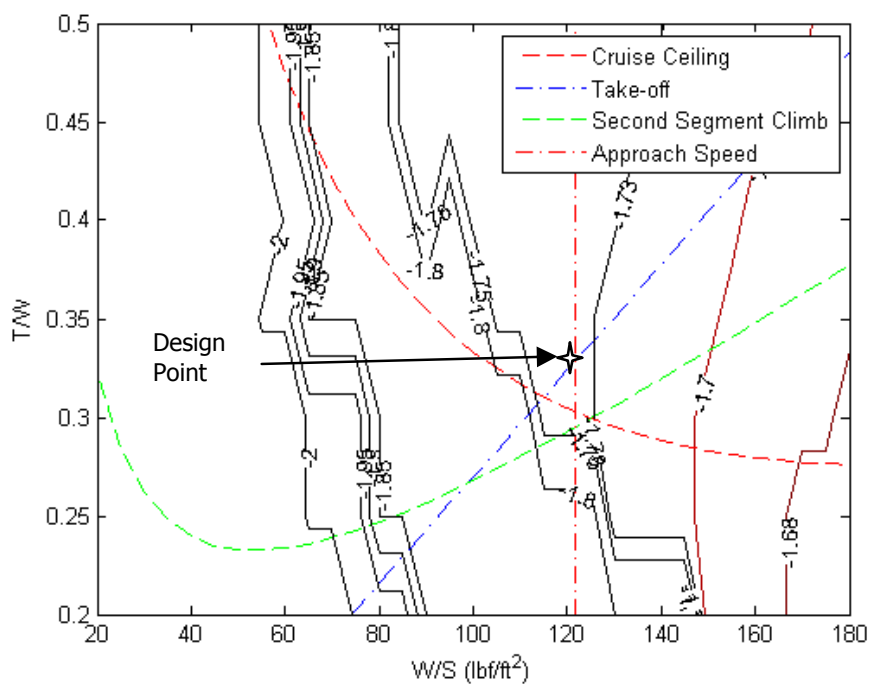

Figure 8: Surplus Value Parameter Contours and Constrains for Notional 150 Passenger Aircraft $\left(1 \times 10^{10} \$ \mathrm{ft}^{-2}\right)$

Again the design point has shifted, unlike the range parameter maximizing point, which is at the intersection of the take-off and cruise constraint. The surplus value maximizing parameter is located at the intersection of take-off and approach speed constraints.

\section{Conclusion}

It is possible to develop an equivalent to the range parameter for maximizing the surplus value of a commercial transport. Instead of minimizing gross weight this parameter maximizes the potential return for an early conceptual design. Further, the design point suggested by this parameter does not always lie at the same point as the one that minimizes gross weight. Because of this the use of the surplus value parameter has the potential to produce a better starting point than either classic constraints analysis alone or constraints analysis plus range parameter. However, the result is just that a starting point for a fully constrained rubberised design. It is a quick what to gauge where an initial guess at thrust-to-weight and wing-loading should be placed. From this point, it is necessary to begin developing a more detailed model of the aircraft, improving both the engineering and value estimates. Furthermore, it is useful to relax or remove the constraints and further design and optimize the aircraft to maximize its value.

\section{References}

1. Raymer DP. Aircraft Design: A Conceptual Approach. Reston: American Institute of Aeronautics and Astronautics; 1999.

2. Nicolai LM, Carichner G. Fundamentals of aircraft and airship design, Volume 1. Reston, VA: American Institute of Aeronautics and Astronautics; 2010 p. 883. Available from: http://books.google.com/books?id=qA0oAQAAMAAJ\&pgis $=1$

3. Mcdonald RA. Mission Performance Considered as Point Performance in Aircraft Design. Journal of Aircraft. 2011;48(5):1576-1587.

4. McCullers LA. FLOPS, Flight Optimization System, Release 8.20. 2011 February. 
5. McCullers LA. Aircraft Configuration Optimization Including Optimized Flight Profiles. Hampton, Va; 1987.

6. Takahashi TT. Optimum Aspect Ratio for Subsonic Air Vehicles. Journal of Aircraft. 2011;48(6):1984-1993.

7. Martinez-val R, Roa J, Perez E, Cuerno C. Effects of the Mismatch Between Design Capabilities and Actual Aircraft Utilization. Journal of Aircraft. 2011;48(6):1921-1927.

8. Collopy PD, Hollingsworth PM. Value-Driven Design. Journal of Aircraft [Internet]. 2011 May [cited 2012 February 13];48(3):749-759. Available from: http://doi.aiaa.org/10.2514/1.C000311

9. Cheung J (University of S, Scanlan J, Wong J, Forrester J, Eres H, Collopy P, Hollingsworth $\mathrm{P}$, Wiseall S, Briceno S. Application of Value-Driven Design to Commercial Aero-Engine Systems. Journal of Aircraft. 2012.

10. Sutcliffe $P$, Hollingsworth $P$. Development of an Airline Revenue Capability Model for Aircraft Design. 10th AIAA Aviation Technology, Integration, and Operations (ATIO) Conference. 2010 September;(AIAA-2010-9059).

11. Hollingsworth P. An Investigation of Value Modelling for Commercial Aircraft. Air Transport and Operations Symposium 2011. 2012:358-371.

12. Collopy PD. Surplus Value in Propulsion System Design Optimization. In: 33rd AIAA/ASME/SAE/ASEE Joint Propulsion Conference and Exhibit. Seattle, WA; 1997. Available from: http://vddi.org/svp.pdf

13. Hess R, Romanoff HP. Aircraft Airframe Cost Estimating Relationships. Study Approach and Conclusions. Santa Monica, CA; 1987. Available from:

http://oai.dtic.mil/oai/oai?verb=getRecord\&amp;metadataPrefix=html\&amp;identifier=ADA2129 20

14. Hess R, Romanoff HP. Aircraft Airframe Cost Estimating Relationships: All Mission Types. Santa Monica, CA; 1987. Available from: http://www.rand.org/pubs/notes/N2283z1.html

15. Hess R, Romanoff HP. Aircraft Airframe Cost Estimating Relationships: Bombers and Transports. Santa Monica, CA; 1987. Available from: http://www.rand.org/pubs/notes/N2283z3.html

16. Liebeck $R$, Andrastek $D$, Chau J. Advanced subsonic airplane design and economic studies. Long Beach, CA; 1995. Available from: http://ntrs.nasa.gov/search.jsp?R=19950017884

17. Mattingly JD, Heiser WH, Daley DH. Aircraft Engine Design. New York: American Institute of Aeronautics and Astronautics; 1987. 